\title{
A PANEL PROJECT ON PURCHASING POWER PARITY: MEAN REVERSION WITHIN AND BETWEEN COUNTRIES
}

Jeffrey A. Frankel

Andrew K. Rose

Working Paper No. 5006

\section{NATIONAL BUREAU OF ECONOMIC RESEARCH \\ 1050 Massachusetts Avenue \\ Cambridge, MA 02138 \\ February 1995}

This work was conducted in part while Rose was a consultant at the IMF Research Department and the US Department of Treasury. This paper was inspired by Flood and Taylor (1994); we thank Robert Flood for many discussions. We also thank; Hali Edison, Joe Gagnon, David Papell, and participants at the 1995 American Economic Association Meetings for comments. This paper is part of NBER's research program in International Finance and Macroeconomics. Any opinions expressed are those of the authors and not those of the National Bureau of Economic Research.

(C) 1995 by Jeffrey A. Frankel and Andrew K. Rose. All rights reserved. Short sections of text, not to exceed two paragraphs, may be quoted without explicit permission provided that full credit, including $\mathbb{0}$ notice, is given to the source. 
NBER Working Paper \#5006

February 1995

\title{
A PANEL PROJECT ON PURCHASING POWER PARITY: MEAN REVERSION WITHIN AND BETWEEN COUNTRIES
}

\begin{abstract}
Previous time-series studies have shown evidence of mean-reversion in real exchange rates. Deviations from purchasing power parity (PPP) appear to have half-lives of approximately four years. However, the long samples required for statistical significance are unavailable for most currencies, and may be inappropriate because of regime changes. In this study, we reexamine deviations from PPP using a panel of 150 countries and 45 annual observations. Our panel shows strong evidence of mean-reversion that is similar to that from long time-series. PPP deviations are eroded at a rate of approximately $15 \%$ annually, i.e., their half-life is around four years. Such findings can be masked in time-series data, but are relatively easy to find in crosssections.
\end{abstract}

Jeffrey A. Frankel

Institute for International Economics

11 Dupont Circle

Washington, DC 20036-1207

and NBER
Andrew K. Rose

Haas School

University of California, Berkeley

Berkeley, CA 94720-1900

and NBER 


\section{I: Introduction}

Purchasing power parity (PPP) is one of the most important theoretical concepts in international economics. Empirical work on the topic most often used time-series data to compare the percentage changes in bilateral exchange rates with inflation differentials. Many early studies were based on short or medium-length time series, often consisting of post- 1973 observations for a few major industrialized countries. They typically did not find strong evidence of PPP. $1 /$ Concerned about inadequate power in their tests, researchers then turned to longer time samples. $\underline{2}$ With longer samples, the evidence has swung back in favor of some long-run tendency toward PPP. At length, consensus has emerged from this literature that there is in fact a moderate tendency for real exchange rates to converge towards a long-run equilibrium. The half-life of PPP deviations appears to be around four years. Froot and Rogoff (1994) provide an excellent critical survey and review of this literature.

This short paper is an empirical re-examination of PPP. Instead of a time-series approach, we use a panel data set of 45 years of annual data for 150 countries. One motivation of the study is to reiterate the point that the ability to find evidence of PPP depends crucially on the total variation in the data used (including both the number of observations and their variability). A second motivation is to avoid concerns about the use of long time series, since they include potentially serious structural shifts. A typical 100year or 200-year sample for the pound/dollar rate, for example, includes several shifts

1/ Exámples include: Roll (1979), Frenkel (1981), Adler and Lehman (1983), Darby (1981), Mishkin (1984), and Piggott and Sweeney (1985).

2/ Examples include Abuaf and Jorion (1990), Edison (1987), Edison and Klovland (1987), Frankel (1986, 1989), Froot and Rogoff (1994), Kim (1990), and Lothian and Taylor (1993). 
between fixed rates, floating, and intermediate regimes. It has been well known since at least Mussa (1986) that real exchange rates behave very differently under different exchange rate regimes. Thus it is reasonable to suppose that the speed of PPP adjustment may also vary with the nature of the exchange rate regimes. Our cross-section approach makes it possible to confine the estimation to the post-1973 period of generalized (dollar) floating, and still have plenty of data for powerful tests. $1 /$

Our panel and cross-sectional estimates turn out to be similar to those found in long time-series data. We estimate that twelve to fifteen percent of PPP deviations are eroded annually. These estimates are statistically significant, and consistent with the existing timeseries literature: by raising .85 to the fourth power we see that our estimate implies that half of a PPP deviation is closed after four years, the same estimate found with time-series techniques. Thus, our findings should be viewed as complementary to and consistent with those of the existing literature. However, cross-sectional data appear to give more powerful evidence of long-run PPP than do time-series. Observations at a typical point in time across countries appear to be "more independent" and certainly have more variation than do observations for a typical pair of countries over time.

1/ This approach has also been pursued independently on smaller panels of post-Bretton Woods OECD data by Lothian (1994), Wei and Parsley (1995), Wu (1994). Consistent with our results, all three find strong evidence that PPP tendencies can be found with panel data. 


\section{II: Methodology}

Our purpose is to compare panel and cross-sectional results with those derived from time-series. To facilitate this comparison, we begin with a standard equation. We estimate:

$$
\Delta \mathrm{s}_{\mathrm{it}}=\alpha+\beta\left(\Delta \mathrm{p}-\Delta \mathrm{p}^{*}\right)_{\mathrm{it}}+\left\{\Sigma_{\mathrm{i}} \delta_{\mathrm{i}} \mathrm{D}_{\mathrm{i}}\right\}+\left\{\Sigma_{\mathrm{t}} \delta_{\mathrm{t}} \mathrm{D}_{\mathrm{t}}\right\}+\epsilon_{\mathrm{it}}
$$

where: $\Delta$ denotes the first-difference operator; i denotes country, and $t$ denotes year; $s$ denotes the natural logarithm of the number of units of foreign exchange needed to purchase one American dollar; $\mathrm{p}\left(\mathrm{p}^{*}\right)$ denotes the natural log of the domestic (American) CPI; $D_{i}\left(D_{j}\right)$ denotes a country-specific (year-specific) "fixed effect" dummy variable intercept; and $\epsilon$ denotes a stationary disturbance term, representing departures from PPP. Throughout, we think of (1) as being a non-structural linear projection.

The coefficient of interest to us is $\beta$. A finding that $\beta$ is statistically indistinguishable from unity constitutes confirmation of PPP (technically speaking "relative" PPP, since the equation is estimated in first-differences of logs). On the other hand, it is not clear what alternative interpretation can be given if $\beta$ is estimated to be different from one. $1 /$

We follow the literature in estimating (1) with ordinary least squares. OLS estimates of $\beta$ are consistent under the hypothesis that PPP deviations are uncorrelated with inflation

1/ For the reasons given in Davutyan and Pippenger (1985), Krugman (1978) and Frankel $(1986,1989)$, we believe that this equation may not be especially revealing. Essentially, under the null hypothesis -- that PPP holds except for random deviations that are small and transitory - it relies on the assumption that PPP deviations are uncorrelated with inflation rates, while it does not make sense at all under the alternative. However, we begin with equation (1) to facilitate comparison with the literature. 
differences. While it is traditional to make such assumptions, they may be implausible. For this reason, we also estimate (1) with instrumental variables, using a time trend and a single lag of both $\Delta \mathrm{e}$ and $\left(\Delta \mathrm{p}-\Delta \mathrm{p}^{*}\right)$ as instrumental variables (following the discussion in Froot and Rogoff).

Equation (1) models the percentage change in the exchange rate as a function of the inflation differential. While informally this direction of causality seems appropriate for countries with floating exchange rates, many countries have fixed their exchange rates for at least part of our sample. In any case, the regression specification is ad hoc, if standard, leaving unresolved potentially important issues of endogeneity, as well as the issue of assuming orthogonality of PPP disturbances to inflation differentials. Thus, we also run the "reverse" regression to equation (1), projecting inflation differentials on exchange rate percentage changes. The potential presence of heteroskedasticity leads us to estimate our coefficient covariance matrix with a White/Huber estimator throughout.

We have no strong prior views about the relevance of country- or time-specific fixed effect terms. We check to ensure that our results are insensitive to their inclusion. Indeed, we perform a number of robustness checks on equation (1). We estimate it: on only post1973 data; on only data for industrialized countries; on data averaged over a number of years; and on observations with only small or large values of the inflation differential (so as to keep track of the relative importance of outlier observations).

We will also provide more direct evidence on mean-reversion in the real exchange rate by estimating the following equation:

$$
\Delta \mathrm{q}_{\mathrm{it}}=\alpha+\gamma \mathrm{q}_{\mathrm{it}-1}+\left\{\Sigma_{\mathrm{i}} \delta_{\mathrm{i}} \mathrm{D}_{\mathrm{i}}\right\}+\left\{\Sigma_{\mathrm{l}} \delta_{\mathrm{l}} \mathrm{D}_{\mathrm{l}}\right\}+\epsilon_{\mathrm{it}}^{\prime}
$$


where $q \equiv s-\left(p-p^{*}\right)$ denotes the natural logarithm of the real exchange rate.

This framework is close in spirit to a traditional time-series Dickey-Fuller test of the proposition that the real exchange rate follows a martingale. Significant negative estimates of $\gamma$ would indicate substantial mean-reversion in the real exchange rate. The limiting case of $\gamma=-1$ represents complete mean reversion (within the year); $\gamma=0$ represents no mean reversion, so that the real exchange rate follows a random walk. However, the panel nature of our set-up means that traditional Dickey-Fuller critical values are inapplicable to test the null hypothesis $\mathrm{H}_{0}: \gamma=0$. Quah (1994) shows that the relevant critical values for "t-like" hypothesis tests concerning $\gamma$ are quite close to normal for our sample, when all intercepts are suppressed. Levin and Lin (1992) generalize Quah's analysis. They show that the critical values which are appropriate in the presence of a single intercept are nearly normal for our sample. However, they also find that inclusion of a set of country-specific intercepts drives the critical values required to reject the hypothesis $H_{0}: \gamma=0$ above 10 in absolute value.

\section{III: The Data Set}

Our data set is annual, and was extracted from the $8 / 93 \mathrm{~cd}$-rom version of the IMF's International Financial Statistics. We use the CPI (IFS line 64) as the measure of prices, and the price of an American dollar (IFS line rf) as the exchange rate. Both of these variables are standard choices for the literature. Series are available for 150 countries, though many countries do not have data which span the full data range, 1948 through 1992 (in which case we use whatever data are available). Throughout, the United States is 
treated as the base country for both prices and exchange rates. Both exchange rates and CPIs are converted by taking first-differences of natural logarithms. 1 /

The raw data set is presented graphically in Figure 1. Each of the nine "small multiple" graphic images is a scatter-plot of the first-difference in the exchange rate against the inflation differential. Individual observations are marked with dots; the dots are connected with a non-linear non-parametric data smoother. A number of the scatter plots are bordered by pairs of box-and-whiskers graphs, one for each marginal distribution (inflation differential above, percentage change in the exchange rate to the right). These graphical representations of the marginal distributions enable one to determine the location of tight clusters of data. $\underline{2}$

The nine graphs represent a number of different cuts at the same data set. The entire panel is portrayed at the extreme top left-hand corner of the figure. However, most of the observations lie within a small area of this graph, owing to the presence of a few outliers which dominate the plot. To allow one to focus on non-outliers, the other graphs on the top row narrow the range of the data plots by restricting the values of exchange rate percentage change to no more than $200 \%$ in absolute value (in the middle) and no more than $25 \%$ (on the right). The right and middle graphs in the center row portray post-1973 and industrial country observations only. The last four graphs portray data averaged over five, ten, twenty, and forty years respectively.

1/ Our STATA data set and programs are available upon receipt of two formatted highdensity $3.5^{\prime \prime}$ diskettes and a self-addressed stamped mailer.

2/ The box covers the inter-quartile range with the median marked explicitly inside; the whiskers extend to $150 \%$ of the inter-quartile range rolled back to the nearest available observation. 
1949-1993, All IFS Countries, Different Frequencies, $\$$ rates and CPIs Non-Parameteric Smoothers also shown

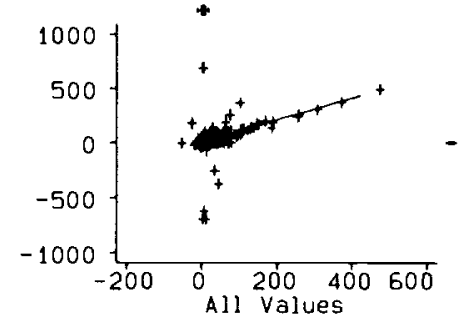

Annual Panel

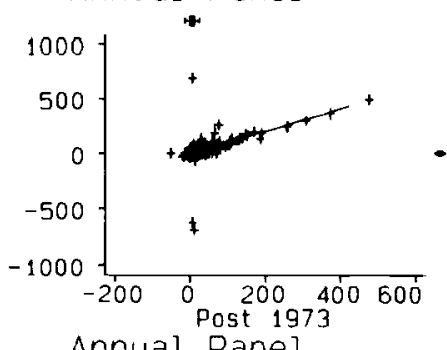

Annual Pane]

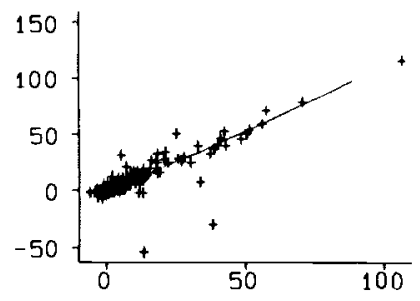

Ten-Year Averages

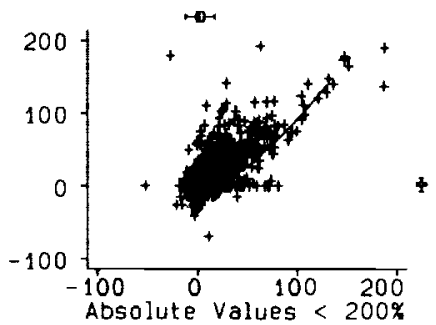

Annual Panel

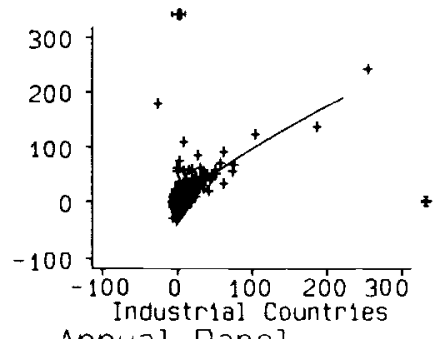

Annual Pane]

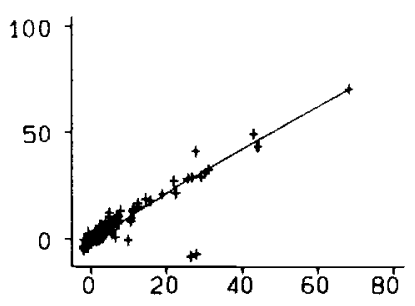

Twenty-Year Averages

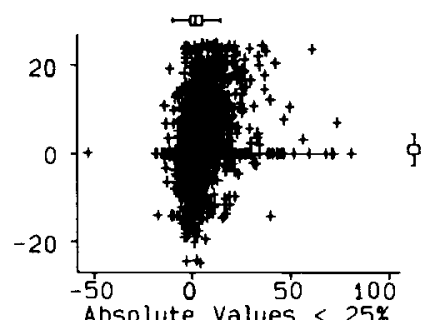

Absolute values $<25 \%$ Annual Panel

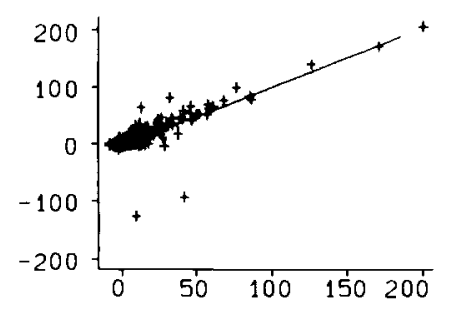

Five-Year Averages

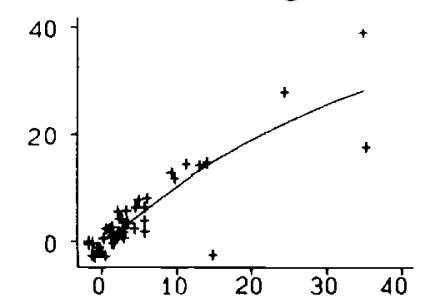

Forty-Year Averages

Exchange Rate Changes Against Inflation Differentials

Raw PPP Panel Data

Figure 1: Raw Panel Data of Exchange Rate Changes on Inflation Differentials

Throughout, there is clear evidence of a strong positive correlation between the percentage change in the exchange rate and the inflation differential. This is especially true when high-inflation observations are included.

Exchange rate percentage changes and inflation differentials have similar sample means over the entire sample (6.7\% and $5.8 \%$ respectively), but very different standard deviations ( $35.0 \%$ and $18.6 \%$ respectively). Moreover, this variation differs systematically across the time- and country-dimensions of the panel data set. Table I contains some 
relevant

descriptive

statistics. It

presents one

aspect of the

Table I: Descriptive Statistics

relative contributions of time-series variation and cross-sectional variation for the two variables. The top panel of the table presents results computed using only the time-series variation in the data, the average (and standard deviation of this average) across the 150 country-specific time-series, and the average standard deviation for these 150 time-series. The bottom panel is the analog for the 44 year-specific cross-sections. The sample means of exchange rate percentage changes and inflation differentials are quite similar across time and countries. However, the typical standard deviation of the data is much higher (for both the regressor and the regressand of equation (1)) across countries than across time. We shall see that the greater variability in the cross-section dimension allows for more powerful tests.

\section{IV: Results}

Table II contains estimates of equation (1). There are three different panels in the table, respectively referring to: benchmark OLS estimates of equation (1) at the top; instrumental variable estimates in the middle; and reverse regressions at the bottom. The different rows correspond to different perturbations of the specification, e.g., including country- or year-specific dummies (i.e., the $\left\{D_{i}\right\}$ and $\left\{D_{t}\right\}$ terms), restricting the sample in various ways, and averaging the data over four different time horizons. The "slope" 
Table II: Estimations of Equation (1), and Perturbations Thereof

Regressions of Percentage Change in Exchange Rate on Inflation Differential

Whole Panel

\begin{tabular}{ccccc}
\multicolumn{2}{c}{ Slope (se) } & $\mathbf{N}$ & $\mathbf{R}^{2}$ & $\sigma$ \\
.97 & $(.03)$ & 4109 & .29 & 28.3 \\
.95 & $(.04)$ & 4109 & .30 & 28.5 \\
.97 & $(.03)$ & 4109 & .31 & 28.0 \\
.99 & $(.02)$ & 2268 & .40 & 28.1 \\
.91 & $(.06)$ & 1129 & .48 & 11.9 \\
.77 & $(.08)$ & 4016 & .05 & 27.7 \\
.63 & $(.07)$ & 3798 & .02 & 26.4 \\
.56 & $(.10)$ & 3395 & .01 & 24.6 \\
1.01 & $(.04)$ & 714 & .44 & 41.5 \\
1.01 & $(.04)$ & 733 & .73 & 9.2 \\
1.01 & $(.06)$ & 330 & .76 & 6.8 \\
.96 & $(.07)$ & 140 & .82 & 4.9 \\
.86 & $(.17)$ & 48 & .76 & 3.9
\end{tabular}

Instrumental Variable Regressions (instrumental variables in parentheses)

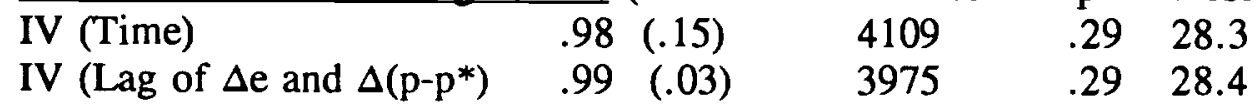

Regressions of Inflation Differential on Percentage Change in Exchange Rate

$\begin{array}{lclccc}\text { Whole Panel } & .30 & (.08) & 4109 & .29 & 15.6 \\ \text { Country Dummies } & .24 & (.07) & 4109 & .42 & 14.3 \\ \text { Year Dummies } & .29 & (.08) & 4109 & .32 & 15.4 \\ \mid \text { Values } \mid<50 \% & .07 & (.02) & 4016 & .05 & 8.3 \\ \mid \text { Values } \mid>10 \% & .44 & (.13) & 714 & .44 & 27.2 \\ \mid \text { Values } \mid>20 \% & .53 & (.12) & 311 & .52 & 33.0 \\ \mid \text { Values } \mid>50 \% & .69 & (.12) & 93 & .70 & 38.1 \\ \text { Post Bretton-Woods } & .41 & (.12) & 2268 & .40 & 17.9 \\ \text { Industrial Countries only } & .53 & (.13) & 1129 & .48 & 9.0\end{array}$

OLS results, heteroskedasticity-consistent standard errors (except for IV results). USA is base country; 1948-1992.

tabulated is the point estimate of $\beta$. The estimated (heteroskedasticity-consistent) standard error is recorded in parentheses. Also tabulated is the sample size "N", the $\mathbf{R}^{2}$ of the regression, and an estimate $\sigma$ of the root-mean squared error of the residual $\epsilon$. 
The results from the top panel are consistent with (relative) PPP in the sense that $\beta$ is typically estimated to be close to unity in economic and statistical terms. (In all cases, $\beta$ is significantly different from zero at traditional confidence levels.) For instance, the top row of Table II indicates that estimation of the most naive form of equation (1) delivers an estimate of $\beta=.97$, essentially indistinguishable from the null hypothesis of $\beta=1$. This result is also relatively insensitive, for example, to inclusion of the different set of fixedeffect intercepts, to restricting the sample to only post-1973 or industrial country data, and to estimation with instrumental variables. These results are quite consistent with those of Lothian (1994) and Wei and Parsley (1995), who both used post-1973 panels of OECD countries. Consistent with Flood and Taylor (1995), averaging the data over time leads to a tight-fitting proportionate relationship between inflation differentials and the change in the exchange rate. Obviously and predictably, $\beta$ falls if outliers are excluded.

The bottom panel of Table II indicates that the bivariate correlation between inflation differentials and exchange rate percentage changes remains significantly greater than zero when the reverse regression is estimated. However, since inflation differentials are much less volatile than exchange rate percentage changes, the regression coefficients are much smaller in the reverse regression specifications. This is one of the reasons we go on to provide further evidence on mean-reversion in the real exchange rate, using (2) as our specification.

It is interesting to compare the time-series and cross-sectional estimates that can be derived from our panel, since the innovation in our study is the addition of the crosssectional variation. Figures 2 and 3 provide some relevant evidence, continuing with the reverse regression as the default specification. Figure 2 is a histogram of the point 


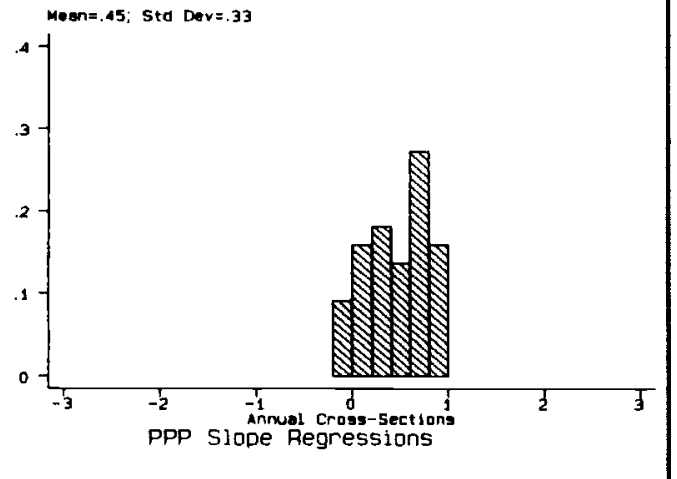

Figure 2: Cross-Section Estimates of $\beta$

The central tendency in $\beta$ derived from the cross-sectional data is both higher and more precise than the central tendency derived only from time-series variation.

Table III contains estimation results for equation (2), the equation which estimates the estimates of $\beta$ which are found from the 44 different cross-sections in the data set, when equation (1) is estimated across countries for a given year. Figure 3 is an analogous histogram of $\beta$ estimates derived using the 150 country-specific time-series in the data.

mean-reversion in the real exchange rate. The three different panels in the table correspond to three different assumptions about the intercepts in equation (2). The top panel suppresses both country- and year-specific intercepts; the middle panel adds countryspecific intercepts; the bottom panel, year-specific intercepts. Each specification is estimated with a variety of restrictions on the data set.1/

In all cases, the point estimate of $\gamma$ is negative. The central tendency is around.- .15 , which implies a half-life of around four years, consistent with the existing time-series literature. It is somewhat more difficult to establish the statistical significance of these

$\underline{1}$ We normalize the real exchange rate by expressing it as the deviation from the countryspecific mean. 
12

Table III: Estimates of Equation (2), and Perturbations Thereof

First-Difference of Log Real Exchange Rate on Lag Log Real Exchange Rate

\begin{tabular}{|c|c|c|c|c|c|}
\hline No Fixed Effects & Slope (se) & $\mathrm{N}$ & $\mathrm{R}^{2}$ & $\sigma$ & \\
\hline Whole Panel & $-.12(.04)$ & & 4109 & .06 & .274 \\
\hline $\mid$ Values $\mid<50 \%$ & $-.01(.004)$ & & 4060 & .00 & .0 \\
\hline $\mid$ Values $\mid>10 \%$ & $-.28(.09)$ & & 923 & .14 & .549 \\
\hline With Lagged Difference & $-.10(.04)$ & & 3975 & .09 & .27 \\
\hline Post Bretton-Woods & $-.12(.06)$ & & 2268 & .05 & .2 \\
\hline Industrial Countries & $-.15(.06)$ & & 1129 & .09 & .1 \\
\hline
\end{tabular}

Country-Specific Intercepts

$\begin{array}{llrll}\text { Whole Panel } & -.12(.04) & 4109 & .07 & .276 \\ \text { |Values| < 50\% } & -.01(.004) & 4060 & .04 & .098 \\ \text { |Values| > 10\% } & -.32(.10) & 923 & .20 & .569 \\ \text { With Lagged Difference } & -.10(.04) & 3975 & .11 & .273 \\ \text { Post Bretton-Woods } & -.40(.14) & 2268 & .25 & .250 \\ \text { Industrial Countries } & -.15(.06) & 1129.11 & .114 \\ & & & & \\ \text { Year-Specific Intercepts } & & & & \\ \text { Whole Panel } & -.12(.04) & 4109 & .09 & .271 \\ \text { |Values| < 50\% } & -.01(.005) & 4060 & .18 & .090 \\ \text { |Values| > 10\% } & -.28(.08) & 923.24 & .530 \\ \text { With Lagged Difference } & -.10(.04) & 3975.12 & .268 \\ \text { Post Bretton-Woods } & -.12(.06) & 2268.08 & .270 \\ \text { Industrial Countries } & -.18(.08) & 1129.45 & .091\end{array}$

OLS results, Huber/White standard errors. USA is base country; 1948-1992.

estimates, because of the complications associated with unit-root tests and panel data sets. Levin and Lin (1992) show that the 5\% critical value for "t-like" tests of $\mathrm{H}_{\mathrm{o}}: \gamma=0$ is around -1.8 when only a single intercept is included; the $1 \%$ value is around -2.4 . Most of our $t$ tests in the top panel exceed these values comfortably. In other words, they reject the hypothesis that the real exchange rate follows a random walk. But while our $t$-ratios do not change much with the inclusion of country-specific fixed effects, the relevant critical values jump enormously, as shown by Levin and Lin. Thus, we are not able to reject the null 
hypothesis of $\mathrm{H}_{\mathrm{o}}: \gamma=0$ when country-specific intercepts are included. On the other hand, neither the fit nor the slope estimates of these regressions seems much affected by the inclusion of country intercepts. $1 /$

Mean reversion in the real exchange rate can be seen in Figure 4, a graphical version of (one estimate of) equation (2). Figure 4 is a scatter plot of the change in the log of the real exchange rate against its lagged level (after allowance for country-specific intercepts); a non-parametric data smoother is also included to help "connect the dots". Evidence of mean-reversion is apparent. For the sake of variety, only post-1973 industrial country data are plotted in Figure 4 . The slope estimate of $\gamma$ is -.18 with a standard

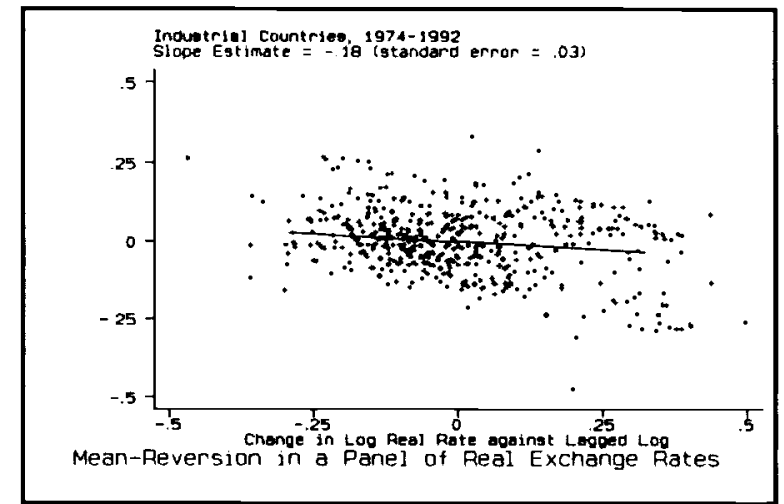

Figure 4: Mean-Reversion in the Real Exchange Rate

error estimated to be .03 (when country-specific intercepts are included). $\underline{2} /$

Next we test pure cross-section and time-series versions of this equation. We perform our analysis for all 19 post-1973 year-specific cross-sections, and for all 131 post1973 country-specific time-series.

For seventeen of the nineteen years, $\gamma$ is estimated to be negative. It is significantly different from zero at the $1 \%$ level in five of these regressions. By way of contrast, only

1/ Levin and Lin do not address the case of time-specific intercepts.

2/ When (2) is estimated on this post-1973 industrialized country panel (with county-specific intercepts), the t-test for $\mathrm{H}_{\mathrm{o}}: \gamma=0$ exceeds 5 . However, when (2) is estimated on a country-by country basis using only the time-series variation in the data, none of the t-tests for $\gamma=0$ is significantly different from zero at the $5 \%$ significance level. 


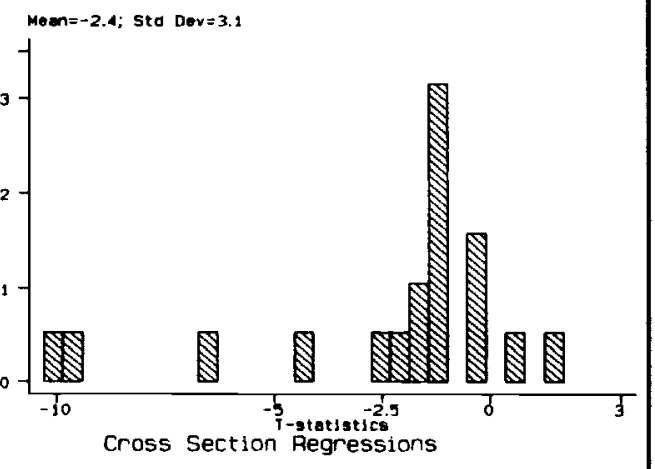

Figure 5: Cross-Sectional t-statistics

our results in support of PPP and reasonable mean-reversion of the real exchange rate are robust to a variety of modifications of our basic empirical methodology. We have also performed, but not reported, a number of additional checks, mostly combinations of our eight of the $\gamma$ are estimates are significantly negative (at the 1\% level) for the 131 timeseries. Histograms of the t-statistics are displayed in Figures 5 and 6 for the 19 crosssections and 131 time-series respectively. We have gone to lengths to show that

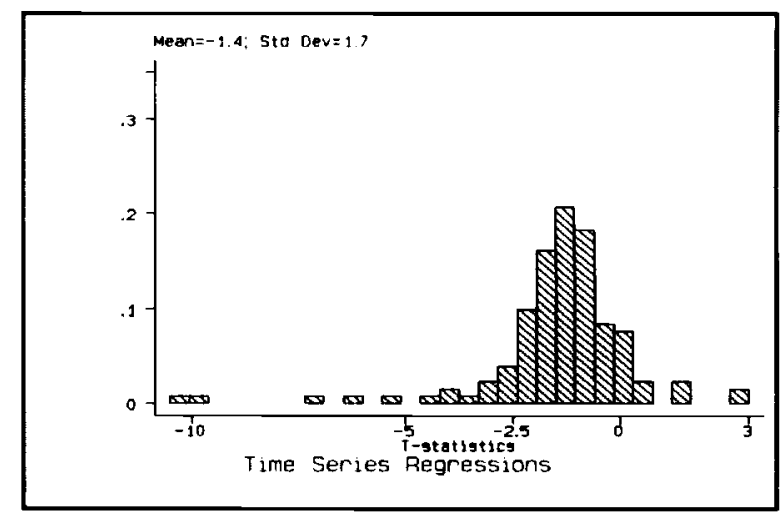

Figure 6: Time-Series t-statistics various restrictions. Our results appear to be quite insensitive. 1 /

\section{V: Why is Variation in the Data So Important?}

The analysis we have presented shows that it is relatively simple to find support for PPP using panel data. This conclusion is at odds with the conventional view that it is not easy to reject the hypothesis that the real exchange rate follows a random walk. In this 
section, we show how it is possible to reconcile our results with those from the time-series literature, once the variation of the data is examined in detail. $\underline{\underline{1}}$

Support for PPP derived from equation (1) consists of a failure to reject the null hypothesis $H_{0}: \beta=1$. as stated above, it is hard to believe that PPP deviations (the $\epsilon$ terms in (1)) are completely uncorrelated with inflation differentials. If PPP deviations are correlated with inflation differentials, then OLS estimates of $\beta$ are biased and inconsistent because of the errors-in-variables problem. However, the null hypothesis of a unit coefficient will emerge, as the size of the PPP deviations becomes sufficiently small relative to the total variation in the data. The reason is that the bias vanishes as data variation rises; see Davutyan and Pippenger (1985). As the descriptive statistics in Table I show, cross-sectional variation is higher than time-series variation. Panel OLS estimation of $\beta$ thus has two advantages over pure time-series regressions: more volatility, and more data.

Consider next tests of equation (2). In this case, support for PPP consists of rejecting the null hypothesis of no mean-reversion in the real exchange rate (i.e., rejecting the random walk hypothesis). It is easy to show that a data set with insufficient total variation may fail to reject the null hypothesis because of inadequate power. A pure timeseries variant of equation (2) can be re-written as a simple autoregression, $\mathrm{q}_{\mathrm{t}}=\phi \mathrm{q}_{\mathrm{t}-1}+\epsilon_{\mathrm{t}}$ (ignoring any intercept). The asymptotic standard error of an estimate of $\phi$ is approximately the square root of $\left(1-\phi^{2}\right) / \mathrm{N}$. If the true speed of adjustment is 15 per cent a year $(\phi=.85)$, a simple calculation suggests that we might require more than a century of

1/ For a complementary approach, see Edison et. al. (1994). 
data to be able to reject the null hypothesis $\mathrm{H}_{0}$ : $\phi=1$ using a time-series approach. $1 /$ It is not very surprising that 45 years of data is not enough, much less the 20 years of data available since 1973. (The gain in power from using a higher frequency data set is small, as shown in Frankel $(1986,1989)$.$) / /$ Again, the message is that the volatile large panel allows one to estimate mean-reversion tendencies with greater precision than short timeseries regressions.

\section{VI: Conclusions}

This paper examines purchasing power parity using a panel data set of 150 countries and 45 annual observations. Our results are consistent with the emerging consensus view that deviations from PPP have a half life of approximately four years. It is difficult to find such results with a pure time-series approach; one is forced to rely on a century of data which, when it is available, straddles different exchange rate regimes. It is much easier to find the requisite variation in the data by exploiting cross-sectional variation.

1/ Since $\left.2.93^{2}\left(1-.85^{2}\right) /(1-.85)^{2}\right]=106$.

2/ Econometricians consider the asymptotic standard error on which this calculation is based to be a bad approximation in small samples. But the correct power calculation suggests that, if anything, the sample required to reject a random walk would be even larger than 106. DeJong, Nankervis, Savin and Whiteman (1988, table II) offer power tables for the DickeyFuller test which show that when the true $\phi$ parameter is .8 , even a sample size of 100 is sufficient to reject a random walk only about 65 per cent of the time. 


\section{References}

Abuaf, Niso, and Philippe Jorion (1990) "Purchasing Power Parity in the Long Run" Journal of Finance 45-1, 157-174.

Adler, Michael and Bruce Lehman (1983) "Deviations from Purchasing Power Parity in the Long Run" Journal of Finance 39-5, 1471-1478.

Darby, Michael (1981) "Does Purchasing Power Parity Work?" Proceedings of the Fifth West Coast Academic/Federal Reserve Economic Research Seminar, Federal Reserve Bank of San Francisco.

Davutyan, N. and J. Pippenger (1985) "Purchasing Power Parity did not Collapse during the 1970s" American Economic Review 75-5, 1151-1158.

DeJong, David, John Nankervis, Eugene Savin and Charles Whiteman (1988) "Integration vs. Trend-Stationarity in Macroeconomic Time Series" Department of Economics Working Paper No.88-27a, University of Iowa.

Edison, Hali J. (1987) "Purchasing Power Parity in the Long Run" Journal of Money, Credit, and Banking 19-3, 376-387.

Edison, Hali J. and Jan Tore Klovland (1987) "A Quantitative Reassessment of the Purchasing Power Parity Hypothesis" Journal of Applied Econometrics 2, 309-333.

Edison, Hali J. Joseph E. Gagnon and William R. Melick (1994) "Understanding the Empirical Literature on Purchasing Power Parity" International Finance Discussion Papers No. 465.

Flood, Robert P. and Mark Taylor (1994) "Exchange Rate Economics: What's Wrong with the Conventional Approach?" forthcoming in The Micro-structure of Foreign Exchange Markets (Frankel, Galli and Giovannini, editors).

Frankel, Jeffrey (1986) "International Capital Mobility and Crowding Out in the U.S. Economy: Imperfect Integration of Financial Markets or of Goods Markets?" in How Open Is the U.S. Economy?, ed. R. Hafer, Lexington: Lexington Books.

Frankel, Jeffrey (1989) "Zen and the Art of Modern Macroeconomics" in Monetary Policy for a Volatile Global Economy, W. Haraf and T. Willett, eds., Washington: AEI.

Frenkel, Jacob (1981a) "Flexible Exchange Rates, Prices and the Role of 'News': Lessons from the 1970s" Journal of Political Economy 89-4, 665-705.

Frenkel, Jacob (1981b) The Collapse of Purchasing Power Parities during the 1970s" European Economic Review 16, 145-65. 
Froot, Kenneth A. and Kenneth Rogoff (1994) "Perspectives on PPP and Long-Run Real Exchange Rates" forthcoming in the third volume of The Handbook of International Economics (Grossman and Rogoff, eds), North Holland.

Kim, Yoonbai (1990) "Purchasing Power Parity in the Long Run: A Cointegration Approach" Journal of Money Credit and Banking 22-4.

Krugman, Paul (1978) "Purchasing Power Parity and Exchange Rates: Another Look at the Evidence" Journal of International Economics 8-3, 397-407.

Levin, Andrew and Chien-Fu Lin (1992) "Unit Root Tests in Panel Data" UCSD working paper.

Lothian, James (1994) "Multi-Country Evidence on the Behavior of Purchasing Power Parity Under the Current Float" unpublished.

Lothian, James, and Mark Taylor (1993) "Real Exchange Rate Behavior: The Recent Float from the Perspective of the Past Two Centuries" Journal of Political Economy forthcoming.

Mishkin, Frederic (1984) "Are Real Interest Rates Equal Across Countries? An Empirical Investigation of International Parity Conditions" Journal of Finance 39, 1345-1358.

Mussa, Michael (1986) "Nominal Exchange Rate Regimes and the Behavior of the Real Exchange Rate" in Real Exchange Rates and Actual Policies (eds: Brunner and Meltzer), North-Holland, New York.

Pigott, Charles and Richard Sweeney (1985) in Exchange Rates, Trade and the U.S. Economy, eds: S. Arndt, R. Sweeney and T. Willett, Washington, D.C.: American Enterprise Institute.

Quah, Danny (1994) "Exploiting Cross-Section Variation for Unit Root Inference in Dynamic Data Economics Letters 44, 9-19.

Roll, Richard (1979) "Violations of Purchasing Power Parity and their Implications for Efficient International Commodity Markets," in M. Sarnat and G. Szego, eds., International Finance and Trade, vol. 1, Cambridge, Mass.: Ballinger.

Wei, Shang-Jin and David Parsley (1995) "Purchasing Power Dis-Parity during the Floating Rate Period: Exchange Rate Volatility, Trade Barriers, and Other Culprits".

Wu, Yangru (1994) "Are Real Exchange Rates Non-Stationary?" Chinese University of Hong Kong working paper. 